Research Paper

\title{
Rutin, a Flavonoid and Principal Component of Saussurea Involucrata, Attenuates Physical Fatigue in a Forced Swimming Mouse Model
}

\author{
Kang-Yi Su ${ }^{2,3 *}$, Chao Yuan Yu1 ${ }^{1 *}$, Yue-Wen Chen ${ }^{1}$, Yi-Tsau Huang ${ }^{4}$, Chun-Ting Chen ${ }^{1}$, Hsueh-Fu Wu ${ }^{1}$, \\ Yi-Lin Sophia Chen ${ }^{1 凶}$ \\ 1. Department of Biotechnology and Animal Science, National Ilan University, Ilan, Taiwan; \\ 2. Department of Clinical Laboratory Sciences and Medical Biotechnology, College of Medicine, National Taiwan University, Taipei 100, Taiwan; \\ 3. Department of Laboratory Medicine, National Taiwan University Hospital, Taipei 100, Taiwan; \\ 4. National Research Institute of Chinese Medicine, Ministry of Health and Welfare, Taipei, Taiwan. \\ * Kang-Yi Su and Chao Yuan Yu contributed equally to this work.
}

$\square$ Corresponding author: Yi Lin Sophia Chen, Department of Biotechnology and Animal Science, National Ilan University, Ilan, Taiwan, 1 , Sec.1, Shen-Lung Road, Ilan City 260. Tel: +886-3-935-7400\# 7625 fax: +886-3-9311526 E-mail: a221865880@yahoo.com.tw (Y. L. S. Chen).

( ) Ivyspring International Publisher. This is an open-access article distributed under the terms of the Creative Commons License (http://creativecommons.org/ licenses/by-nc-nd/3.0/). Reproduction is permitted for personal, noncommercial use, provided that the article is in whole, unmodified, and properly cited.

Received: 2013.II.26; Accepted: 2014.03.05; Published: 2014.03.29

\begin{abstract}
This study investigated the antifatigue effects of rutin, a flavonoid extracted from the ethyl acetate extract of $S$. involucrata. Mice were subjected to a weight-loaded forced swim test (WFST) on alternate days for $3 \mathrm{wk}$. Rutin was administered orally to the mice for 7 days in dosages of 15, 30, and $60 \mathrm{mg} / \mathrm{kg}$ body weight, and several biomarkers of physical fatigue were evaluated: swimming time, change in body weight, lipid peroxidation, lactic acid (LA), glycogen, and the activities of the antioxidant enzymes superoxide dismutase (SOD) and glutathione peroxidase (GPx). On Day 7, the rutin-treated mice had a 3 -fold longer exhaustive swimming time than the control mice, as well as significantly reduced blood LA concentrations. The 15,30 , and $60 \mathrm{mg} / \mathrm{kg}$ body weight rutin-supplemented groups displayed II.2\%, 22.5\%, and 37.7\% reduced malondialdehyde (MDA) concentrations, respectively, in brain and muscle tissues compared with the control exercised group. Our results indicated that the administration of rutin protected the mice against the depletion of SOD and GPx activities significantly. Following 7 days of rutin treatment, we sacrificed the mice and analyzed their soleus muscle and brain for peroxisome proliferator-activated receptor- $\alpha$ coactivator (PGC-I $\alpha$ ) and sirtuin I (SIRTI) mRNA expression. We observed that rutin treatment increased PGC-I $\alpha$ and SIRTI mRNA and protein expression. The changes in these markers of mitochondrial biogenesis were associated with increased maximal endurance capacity. The application of 2D gel electrophoresis to analyze the rutin-responsive protein profiles in the WFST mouse brain further revealed the upregulation of the $C B I$ cannabinoid receptor-interacting protein I, myelin basic protein, Rho GDP dissociation inhibitor (GDI) alpha, and TPI, indicating that rutin might inhibit anxiety through the upregulation of the expression of anxiety-associated proteins. Western blot analysis of MAPK expression further confirmed the antianxiety effects of rutin. Our study results thus indicate that rutin treatment ameliorates the various impairments associated with physical fatigue.
\end{abstract}

Key words: rutin, S. involucrate, physical fatigue

\section{Introduction}

In recent years, the public has become increasingly health-conscious, with an increased proportion of people exercising routinely to increase their physi- cal fitness and prevent sedentary lifestyle-related diseases. Moderate exercise can contribute to the prevention of illness and mental stress; however, 
overexercise provides a form of stress, causing fatigue or various types of damage to organs. Fatigue is a symptom that indicates that a person's health is about to be, or has been, compromised [1]. An alternative term for physical fatigue is peripheral fatigue, which might be accompanied by deterioration in performance [2]. Two mechanisms, oxidative stress and exhaustion, play important roles in physical fatigue [3]. Intense exercise can induce the production and accumulation of excess reactive free radicals, resulting in oxidative stress injury to the body. Exhaustion theory suggests that a depleted energy source and excess metabolite accumulation can cause fatigue [4]; however, studies have also shown that exogenous antioxidants can reduce exercise-induced oxidative stress [5]. Research into specific nutrients or herbal supplements is, therefore, required to identify agents that can reduce metabolite production and/or increase energy potential.

Saussurea Involucrata (Kar. et Kir.) (S. involucrata), otherwise known as the snow lotus, grows in rocky habitats on mountains at $2600 \mathrm{~m}$ elevation or higher in the Tian Shan and A'er Tai regions of China. In folk medicine, it is used to treat rheumatoid arthritis, impotence, irregular menses, cough with cold, stomachache, altitude sickness, and other conditions. Previous studies have shown that the ethyl acetate extract of $S$. Involucrata (SI-2) exerts a potent inhibitory effect on EGFR phosphorylation and activation, and on the AKT and STAT3 pathways, in PC-3 cells [6]. These effects could potentially offer therapeutic advantages in the treatment and prevention of human prostate cancer. Rutin $\left(3,3^{\prime}, 4^{\prime}, 5,7\right.$-pentahydroxyflavone-3rhamnoglucoside; Table 1) is a flavonoid of the flavonol type that occurs plentifully in S. Involucrata. Previous studies have reported that rutin displays several pharmacological properties, including antioxidant, anticarcinogenic, cytoprotective, antiplatelet, antithrombotic, vasoprotective, cardioprotective, and neuroprotective activities [7-10]. In our previous study, we investigated the protective effects of SI-2 or rutin on D-galactose (D-gal)-induced brain injury in mice[11]. Several investigations have used mice injected with D-gal as an animal model of oxidative stress. We identified that administering SI-2 or rutin $(30 \mathrm{mg} / \mathrm{kg} / \mathrm{d})$ for $6 \mathrm{wk}$, concomitant with D-gal injection, increased superoxide dismutase (SOD) and glutathione peroxidase (GPx) activities significantly and reduced plasma malondialdehyde (MDA) concentrations. Our results also showed that the oral administration of rutin significantly improved mouse behavioral performance in a step-through passive avoidance task. These results suggested that rutin exerts potent antiaging effects on D-gal in mice through antioxidative mechanisms.
Exercise is typically considered the optimum strategy to increase muscle mitochondrial number and function; however, little is known concerning the effects of exercise on brain mitochondria [12, 13]. Natural flavonoids, such as resveratrol, and other drugs increase mitochondrial biogenesis by upregulating the transcriptional coactivator sirtuin 1 (SIRT1) and the peroxisome proliferator-activated receptor-1a coactivator (PGC-1 $\alpha$ ) [14-17]. PGC-1a is considered the master regulator of mitochondrial biogenesis, and SIRT1 physically interacts with and deacetylates PGC-1 $\alpha$ to increase PGC-1 $\alpha$ activity $[18,19]$. Given the structural similarities among rutin, resveratrol, and other flavonoid derivatives that increase mitochondrial biogenesis $[14,16,17]$, as well as evidence of the effects of rutin on the energetics of isolated mitochondria in vitro $[17,20,21]$, we hypothesized that rutin would increase mitochondrial biogenesis in muscle and that this effect would be associated with increased exercise tolerance.

Therefore, the purpose of this study was to evaluate the effects of short-term rutin supplementation, in doses that are safe and practical for dietary supplementation, on mitochondrial biogenesis in the soleus muscle, endogenous antioxidant enzyme activities, and endurance exercise tolerance. We selected the soleus muscle because of its relevance to endurance exercise capacity. We used an experimental mouse model to examine the effects of 7 days rutin supplementation on markers of mitochondrial biogenesis, including PGC-1a and SIRT1 gene expression. We also investigated the effects of rutin supplementation on exercise tolerance using the weight-loaded forced swim test (WFST). Overall, this study aimed to evaluate the antifatigue properties of rutin using forced swimming exercise in mice and to identify the mechanisms underlying its actions.

\section{Materials and methods}

\section{Preparation of Fractions}

The wild plant of $S$. involucrata used in this study was a gift from Biopure Biotechnology (Changhua, Taiwan). Twenty grams of dried and powdered aerial parts, including flower, of S. involucrate was extracted with $100 \mathrm{~mL}$ of methanol three times under reflux for $2 \mathrm{~h}$, respectively. The methanol extracts (SI-1) were combined, and the solvent was evaporated in vacuum to give a deep brown syrup. The syrup was resuspended in water and then partitioned successively with pentane, ethyl acetate (SI-2) and n-butanol (SI-3) to leave a water layer (SI-4). The solvents were evaporated respectively, and the residues were used throughout this study. 


\section{Reverse-Phase High-Performance Liquid Chromatography (HPLC) Analysis of Flavonoids in S. involucrata}

The determination of flavonoids from S. involucrata was carried out by HPLC with a photodiode detector. The HPLC system consisted of a Shimadzu LC-20AT solvent delivery system, equipped with a SPD-M20A photodiode array detector, set at $270 \mathrm{~nm}$. Samples were injected with SiL-20A autosample to separate on the TSK-Gel ODS-100S column. The column was maintained at an ambient temperature of $25^{\circ} \mathrm{C}$. The flow rate of the system was $1.0 \mathrm{~mL} / \mathrm{min}$. The mobile phase consisted of solvent A $(0.3 \%$ formic acid) and solvent $B$ (acetonitrile). The elution profile for A was 0-10 min, with a linear gradient change of $0-5 \% ; 10-40 \mathrm{~min}$, with a linear gradient change to $55 \%$; and maintained for another $10 \mathrm{~min}$ with a post run time to equilibrate the column and for the baseline to return to the normal and initial working conditions.

\section{Chemicals and reagents}

Rutin was dissolved in DMSO to a concentration of $50 \mathrm{mM}$ and stored in $-20^{\circ} \mathrm{C}$ as a master stock solution. Dimethyl sulfoxide (DMSO), 3-(4,5-dimethyl thizol-2-yl)-2,5-diphenyl tetrazolium bromide (MTT), 2',7'-dichlorofluorescein diacetate $\left(\mathrm{H}_{2}\right.$ DCF-DA), Hoechst 33342, Thiobarbituric Acid (TBA), Hydrogen peroxide $\left(\mathrm{H}_{2} \mathrm{O}_{2}\right)$, Trichloroacetic Acid,(TCA), Malondialdehyde (MDA), Propidium Iodine (PI) and actin antibody were purchased from Sigma Chemical Co. (St. Louis, MO, USA). NuPAGE Bis-Tris Electrophoresis System (pre-cast polyacrylamide mini-gel) was purchased from Invitrogen (Carlsbad, CA, USA). COX-2 antibody was purchased from Thermo scientific (Waltham, MA, USA). PARP antibodies and horseradish peroxidase - conjugated anti-mouse or anti-rabbit IgG secondary antibodies were purchased from Cell signaling (MA, USA). Polyvinyldenefluoride (PVDF) membranes, BSA protein assay kit and Western blot chemiluminescence reagent were purchased from Amersham Biosciences (Arlington Heights, IL). Superoxide dismutase activity assay kit was purchased from biovision (Mountain View, CA). Glutathione peroxidase assay kit was purchased from Cayman Chemical (MI, USA). DNA Fragmentation Assay Kit was purchased from Clontech Laboratories (Mountain View, CA). Non-Radioactive Cytotoxicity Assay was purchased from Promega (Madison, WI, USA)

\section{Animal experiments}

Specific pathogen free male ICR mice (5 weeks old) were purchased from National Sciences Council (Taipei, Taiwan) and all procedures were performed in compliance with the standard operating proce- dures of the Laboratory Animal Center of Ilan University (Ilan, Taiwan). All animals were given a standard laboratory diet (no. 5001; PMI Nutrition International, Brentwood, MO, USA) and distilled water ad libitum and housed at room temperature $\left(23 \pm 1{ }^{\circ} \mathrm{C}\right)$ with a $12 \mathrm{~h}$ light/12 h dark cycle (lights on from 6:00AM to 6:00 PM). Mice were divided into 4 groups ( $\mathrm{n}=8$ per group in each test) for treatment: (1) vehicle, (2) $15 \mathrm{mg} / \mathrm{kg}$ rutin (3) $30 \mathrm{mg} / \mathrm{kg}$ rutin (4) $60 \mathrm{mg} / \mathrm{kg}$ rutin. Vehicle or rutin was given once by oral gavage for 7 days each. The control group received the same dose of vehicle.

\section{Forced Swimming Test}

The protocol was adapted from a previous study with some modifications. Mice were pretreated with vehicle, $15,30,60 \mathrm{mg} / \mathrm{kg}$ rutin for 7 days and $1 \mathrm{~h}$ after the last treatment administration and underwent an exhaustive swimming test. The mice were placed individually in a columnar swimming pool (length 65 $\mathrm{cm}$ and radius $20 \mathrm{~cm}$ ) with $40 \mathrm{~cm}$ water depth maintained at $37 \pm 1 \circ \mathrm{C}$. A weight equivalent to $5 \%$ of body weight was attached to the root of mouse tail, and endurance for each mouse was measured as swimming times recorded from the beginning of the time in the pool to exhaustion. The swimming period was considered the time spent floating, struggling, and making necessary movements until exhaustion and possible drowning. When the mice were unable to remain on the water surface, they were considered exhausted.

\section{Measurement of MDA content and antioxidant enzyme activities}

The content of MDA was determined using the thiobarbituric acid method. Equal volumes of $0.67 \%$ thiobarbituric acid reagent was added to the sample supernatant and boiled for $10 \mathrm{~min}$ at $100{ }^{\circ} \mathrm{C}$, and cooled, the absorbance of each supernatant was measured at $532 \mathrm{~nm}$. MDA content was calculated by MDA standard. Antioxidant enzyme activities were assayed with Superoxide dismutase activity assay kit (Biovision) and Glutathione peroxidase assay kit (Cayman). The assay was in accordance with the manufacturer's instructions.

\section{Determination of Blood Biochemical Variables}

We evaluated the effects of rutin on plasma lactate and glucose levels after exercise. A 15min swimming test was performed $1 \mathrm{~h}$ after the last treatment administration. Blood samples were collected from the submandibular duct of pretreated mice after the 15 min swimming test. The plasma was prepared by centrifugation at $1500 \times \mathrm{g}, 4 \circ \mathrm{C}$ for $10 \mathrm{~min}$. Lactate and glucose levels were determining by use of an autoanalyzer (Hitachi 7060, Hitachi, Japan). 


\section{Western blot analysis and quantification}

The cells were lysed on ice with $200 \mathrm{ml}$ of lysis buffer $(50$ mMTris- $\mathrm{HCl}, \mathrm{pH} 7.5,0.5 \mathrm{M} \mathrm{NaCl}, 5 \mathrm{mM}$ $\mathrm{MgCl} 2,0.5 \%$ nonidet $\mathrm{P}-40,1 \mathrm{mM}$ phenylmethylsulfonyl fluoridefor, $1 \mathrm{mg} / \mathrm{ml}$ pepstatin, and 50 $\mathrm{mg} / \mathrm{ml}$ leupeptin) and centrifuged at $13,000 \mathrm{~g}$ at $4{ }^{\circ} \mathrm{C}$ for $20 \mathrm{~min}$. The protein concentrations in the supernatants were quantified using a BSA Protein Assay Kit. Electrophoresis was performed on a NuPAGE Bis-Tris Electrophoresis System using $50 \mathrm{mg}$ of reduced protein extract per lane. Resolved proteins were then transferred to polyvinyldenefluoride (PVDF) membranes. Filters were blocked with 5\% non-fat milk overnight and probed with appropriate dilution of primary antibodies for $1 \mathrm{~h}$ at room temperature. Membranes were washed with three times with $0.1 \%$ Tween 20 and incubated with HRP-conjugated secondary antibody for $1 \mathrm{~h}$ at room temperature. All proteins were detected using Western Lightning ${ }^{\mathrm{TM}}$ Chemiluminescence Reagent Plus and the result was quantitated by scanning densitometry using a Bio-Rad model 620Video Densitometer with a 1-D Analyst software package for Macintosh.

\section{Two-dimensional gel electrophoresis (2-DE), gel staining and image analysis}

Approximately $1 \times 10^{6}$ cells were cultured in 60-mm2 dishes and then incubated in $20 \mu \mathrm{M}$ GW-H1 for the indicated time. The cells were lysed on ice with $200 \mu \mathrm{l}$ of lysis buffer (7 M urea, $2 \mathrm{M}$ thiourea, $4 \%$ CHAPS, 100 mM DTT, 2\% pH 3-10 ampholyte), 2-DE was performed according to the method of O'Farrell with slight modifications. Aliquots (200 g) of the cell lysates were resolved in $125 \mu \mathrm{l}$ of rehydration buffer [8 M urea, 4\% CHAPS, 0.5\% IPG 4-7 buffer, and 18.2 $\mathrm{mM}$ dl-dithiothreitol (DTT)] and were loaded onto 7-cm Immobiline DryStrips ( $\mathrm{pH} 4-7$, linear; GE Healthcare, Chalfont St Giles, UK) for the first-dimension isoelectric focusing (IEF). Sample application and gel rehydration were managed in one step $(14 \mathrm{~h}, 30 \mathrm{~V})$ on an IPGphor (GE Healthcare). IEF was conducted with a total of $13,400 \mathrm{~V} h$ at an end voltage of 5000 as follows: 300 and $500 \mathrm{~V}$ constant each for $0.5 \mathrm{~h}$; gradient $500-1000 \mathrm{~V}$ over $0.5 \mathrm{~h}$; gradient $1000-5000 \mathrm{~V}$ over $2 \mathrm{~h}, 5000 \mathrm{~V}$ constant to the desired V $h$. Focused proteins were reduced and alkylated during the equilibration step, immediately prior to the second dimension. Equilibration, $15 \mathrm{~min}$ in $50 \mathrm{mM}$ Tris (pH 8.8), $6 \mathrm{M}$ urea, 30\% glycerol, 2\% SDS, $75 \mathrm{mM}$ DTT followed by $15 \mathrm{~min}$ in an identical buffer with DTT replaced by $135 \mathrm{mM}$ iodoacetamide. The second dimension was performed on $12.5 \%$ SDS-polyacrylamide gels using the Protean III System (Bio-Rad), as described by Laemmli. 2-DE gels were stained with Coomassie Brilliant Blue G-250 (CBB G-250), scanned with the ImageScanner ver. 5.0, and analyzed with the Prodigy SameSpots software ver. 6.0 (Nonlinear). All 2-DE analyses were performed on triplicate repeats. Spots were compared based on their volume percentages in the total spot volume over the whole gel image. Proteins were considered significantly altered if difference in spot intensity was more than 1.5 fold.

\section{In-gel trypsin digestion}

In-gel trypsin digestion was performed according to our previous report with slight modifications. Protein spots of interest were excised, cut into about 1 $\mathrm{mm} \times 1 \mathrm{~mm}$ pieces and placed in a microcentrifuge tube. $100 \mu \mathrm{L}$ of $50 \mathrm{mM}$ DTT in $25 \mathrm{mM}$ ammonium bicarbonate $(\mathrm{pH} 8.5)$ was added into the tube and shaken at $37{ }^{\circ} \mathrm{C}$ for $1 \mathrm{~h}$. After removal of excess DTT by centrifuge, $100 \mu \mathrm{l}$ of $100 \mathrm{mM}$ iodoacetamide (IAA) in $25 \mathrm{mM}$ ammonium bicarbonate $(\mathrm{pH}$ 8.5) was added and the tube was shaken for $30 \mathrm{~min}$ at RT in the dark environment. Then excess IAA was removed by centrifuge. $100 \mu \mathrm{l}$ of $50 \%$ acetonitrile in $25 \mathrm{mM}$ ammonium bicarbonate buffer ( $\mathrm{pH}$ to 8.5 ) was added and the gel pieces were soaked for $15 \mathrm{~min}$, then the buffer was removed completely. The destaining step was repeated twice or more depending on the intensity of the dye. The gel pieces were soaked in $100 \mu \mathrm{l}$ of $100 \%$ acetonitrile for $5 \mathrm{~min}$ and dried by SpeedVac to remove the remaining acetonitrile. Trypsin $(0.1 \mu \mathrm{g})$ in 10 $\mu 125 \mathrm{mM}$ ammonium bicarbonate ( $\mathrm{pH}$ 8.5) was added to the gel pieces, and digestion was performed for 16 $\mathrm{h}$ at $37{ }^{\circ} \mathrm{C} .50 \mu \mathrm{l}$ of $50 \%$ acetonitrile in 5\% TFA was added to quench the trypsin digestion and the solution was sonicated for $10 \mathrm{~s}$ to release the tryptic peptides from the gel. The peptide solution was concentrated and collected for further LC-MS/MS analysis.

\section{LC-nano ESI-Q-TOF MS/MS analysis}

The resulting peptide mixture was subjected to the CapLC system (Waters, Milford, MA,) utilizing a capillary column $(75 \mathrm{~m}$ i.d., $10 \mathrm{~cm}$ in length, C SUN, Taiwan) with a linear gradient from $5 \%$ to $50 \%$ acetonitrile containing $0.1 \%$ formic acid over $46 \mathrm{~min}$. The separated peptides were on-line analyzed under positive survey scan mode on a nano-ESI Q-TOF (Micromass, UK) instrument as previously described [24]. The scan range was from m/z 400 to 1600 for MS and $\mathrm{m} / \mathrm{z} 50$ to 2000 for MS/MS. The raw data was processed into a text file format of PKL with MassLynx 4.0 (subtract 30\%, smooth 3/2 Savitzky Golay and center three channels $80 \%$ centroid).

\section{Protein identification}

For protein identification, the PKL files generated from MS/MS spectra were uploaded to 
MASCOT search engine v2.2 (Matrix Science, UK) (http://www.matrixscience.com). The parameters for database search were as follows: Protein database was set to be NCBInr. Taxonomy was set as eubacteria. One trypsin missed cleavage was allowed. The mass tolerance was set to be 0.4 Da for both precursor and product ions. Carbamidomethyl (C) was chosen as a fixed modification. Deamidated (NQ) and oxidation (M) were chosen for variable modifications. Data format was chosen as Micromass (.pkl) and instrument was chosen as ESI-QUAD-TOF. The proteins with the scores above the significant threshold ( $p<$ 0.05 ) are shown as identified proteins.

\section{Statistical analysis}

Data were shown as mean with standard deviation. The statistical difference was analyzed using the Student's t-test for normal distributed values and by non-parametric Mann-Whitney t-test for values of non-normal distribution. Values of $p<0.05$ were considered significant. Behavioral data were analyzed with one-way analysis of variance (ANOVA), followed by post-hoc Dunnett's $t$ test or Newman-Keul's multiple comparison tests. The $\mathrm{q}$ values represent those calculated from separate sets of Newman-Keul's analysis.

\section{Results}

\section{Effects of rutin on body weight and swimming time}

Table 1 displays the changes in mouse body weight during the experimental period. The sedentary and rutin-supplemented groups showed greater weight gains than the control group. We evaluated the antifatigue effects of rutin according to the swimming endurance capacities of the mice. On Day 7, the rutin treatment groups had longer swimming times than the control group $(P<0.05)$, with a maximum rec- orded swimming time of $41.6 \mathrm{~min}$ in the mice treated with $60 \mathrm{mg} / \mathrm{kg}$ rutin (compared with $29.3 \mathrm{~min}$ in the control group; Table. 1).

\section{Effects of rutin and exercise on mouse plasma LA and glucose concentration}

Endurance exercise reduced glycogen levels in the control group. Rutin supplementation increased the mouse plasma glucose concentrations compared to the controls $(P<0.05)$. In the vehicle, and 15 $\mathrm{mg} / \mathrm{kg}, 30 \mathrm{mg} / \mathrm{kg}$, and $60 \mathrm{mg} / \mathrm{kg}$ rutin groups, plasma glucose levels were $152 \pm 4.5,164 \pm 0.9,183 \pm 8$, and $213 \pm 14 \mathrm{mg} / \mathrm{dL}$, respectively (Table 1 ), and were 1.4-fold higher in mice treated with $60 \mathrm{mg} / \mathrm{kg}$ rutin than in the control group $(P<0.05)$. In the control group, exhaustive swimming increased plasma LA concentrations significantly compared with the sedentary group $(P<0.01$ and $P<0.05$, respectively). The rutin-supplemented groups displayed lower blood LA concentrations than the control mice $(P<0.01$; Table 2). In the vehicle, and 15, 30, and $60 \mathrm{mg} / \mathrm{kg} \mathrm{ru}-$ tin groups, blood lactate concentrations were $3.6 \pm 1.4$, $3.6 \pm 1.5$, and $3.4 \pm 1.2,3.2 \pm 1.7 \mathrm{mmol} / \mathrm{L}$, respectively (Table 2). In the $60 \mathrm{mg} / \mathrm{kg}$ rutin group, LA clearance accelerated significantly after swimming $(P<0.01)$.

\section{Effects of rutin on lipid peroxidation and antioxidant enzyme activity}

Thiobarbituric acid-reactive substances (TBARS) such as MDA are indicators of lipid peroxidation. In this study, the swimming exercise group displayed significantly higher plasma MDA concentrations $(43.7 \%)$ than the control group. However, the brain tissue of the control animals displayed non-significant MDA concentrations (data not shown). The rutin-supplemented mice showed significantly higher SOD $(16.3 \%)$ and GPx (31\%) activities than the control mice $(P<0.05$; Table 3$)$.

Table I. Effect of rutin on swim exercise performance in mice. Mice were pretreated with vehicle or I5, 30 or $60 \mathrm{mg} / \mathrm{kg}$ rutin (R-I5, R-30 or R-60) for 7 days and then I h later underwent an exhaustive swimming test with a $5 \%$ bodyweight load attached to the mouse tail. Data are mean \pm SEM $(\mathrm{n}=10$ mice). $* \mathrm{P}<0.05, * * \mathrm{P}<0.001$ compared to vehicle control.

\begin{tabular}{cccccc}
\hline Group & $\begin{array}{c}\text { Rutin } \\
(\mathrm{mg} / \mathrm{kg})\end{array}$ & $\begin{array}{c}\text { Initiation weight } \\
(\mathrm{g})\end{array}$ & $\begin{array}{c}\text { Final Weight } \\
(\mathrm{g})\end{array}$ & $\begin{array}{c}\text { Swimming Time } \\
(\mathrm{minutes})\end{array}$ & $\begin{array}{c}\text { Glucose } \\
(\mathrm{mg} / \mathrm{dL})\end{array}$ \\
\hline Control & 0 & $31.2 \pm 2.6$ & $32.8 \pm 1.4$ & $29.3 \pm 7.1$ & $152 \pm 4.5$ \\
Fatigue model & 0 & $31.6 \pm 2.9$ & $33.2 \pm 1.0$ & $24.5 \pm 8.6$ & $135 \pm 6.0$ \\
R-15 & 15 & $31.8 \pm 2.2$ & $32.4 \pm 1.9$ & $31.2 \pm 4.7$ & $164 \pm 9.0^{*}$ \\
R-30 & 30 & $31.8 \pm 1.3$ & $32.0 \pm 2.2$ & $39.8 \pm 6.2^{*}$ & $183 \pm 8.0^{* *}$ \\
R-60 & 60 & $31.9 \pm 1.3$ & $33.1 \pm 1.2$ & $41.6 \pm 4.5^{* *}$ & $213 \pm 14^{* *}$ \\
\hline
\end{tabular}


Table 2. Effect of rutin on plasma lactate and glucose levels and after exercise. Mice were pretreated with vehicle or (R-I5, R-30 or R-60) for 7 days and then I h later underwent a 15 min swim test. Data are mean \pm SEM ( $n=10$ mice). (a) Lactate: $* P<0.005$, $* * P<0.000$ I compared to vehicle control. (b) Glucose: $* P<0.05$, $* * P<0.000$ l compared to vehicle control.

\begin{tabular}{cccccc}
\hline Group & $\begin{array}{c}\text { Rutin } \\
(\mathrm{mg} / \mathrm{kg})\end{array}$ & $\begin{array}{c}\text { Initiation lactic acid } \\
(\mathrm{mg} / \mathrm{L})\end{array}$ & $\begin{array}{c}\text { lactic acid after } \\
\text { swimming (mg/L) }\end{array}$ & $\begin{array}{c}\text { Final lactic } \\
\text { acid(mg/L) }\end{array}$ & $\begin{array}{c}\text { lactic acid } \\
\text { clearance }\end{array}$ \\
\hline Control & 0 & $3.1 \pm 0.4$ & $6.0 \pm 2.3$ & $3.6 \pm 1.4$ & 0.405 \\
Fatigue model & 0 & $2.9 \pm 0.4$ & $6.1 \pm 1.2$ & $3.7 \pm 0.8$ & $3.6 \pm 1.5$ \\
R-15 & 15 & $3.0 \pm 0.3$ & $6.0 \pm 2.1$ & $3.4 \pm 1.2$ & 0.400 \\
R-30 & 30 & $3.1 \pm 0.2$ & $6.2 \pm 2.7$ & $3.2 \pm 1.7$ & $0.452^{*}$ \\
R-60 & 60 & $3.1 \pm 0.4$ & $6.2 \pm 1.9$ & & $0.484^{* *}$ \\
\hline
\end{tabular}

Table 3. Effect of rutin on plasma MDA level and SOD and GPx activities in weight-loaded forced swim test (WFST) mice. Mice were pretreated with vehicle or (R-I5, R-30 or R-60) for 7 days and then I h later underwent an exhaustive swimming test with a $5 \%$ body weight load attached to the mouse tail. Plasma MDA level and SOD and GPx activities were determined. (a) MDA: $* P<0.005, * * P<0.000$ I compared to vehicle control. (b) SOD activity: $* P<0.05$ compared to vehicle control. (c) GPx activity: $* P<0.05$ compared to vehicle control.

\begin{tabular}{ccccc}
\hline Group & $\begin{array}{c}\text { Rutin } \\
(\mathrm{mg} / \mathrm{kg})\end{array}$ & $\begin{array}{c}\mathrm{MDA} \\
(\mathrm{mmol} / \mathrm{mL})\end{array}$ & $\begin{array}{c}\text { SOD } \\
(\mathrm{U} / \mathrm{mL})\end{array}$ & $\begin{array}{c}\mathrm{GPx} \\
(\mathrm{U} / \mathrm{mL})\end{array}$ \\
\hline Control & 0 & $28.6 \pm 2.5$ & $118.4 \pm 9.2$ & $2.0 \pm 0.4$ \\
Fatigue model & 0 & $32.6 \pm 3.4$ & $108.7 \pm 10.2$ & $1.5 \pm 0.6$ \\
R-15 & 15 & $27.5 \pm 2.2$ & $122.4 \pm 3.9^{*}$ & $2.2 \pm 0.2^{*}$ \\
R-30 & 30 & $22.8 \pm 1.9^{*}$ & $135.0 \pm 7.2^{*}$ & $2.6 \pm 0.4^{*}$ \\
R-60 & 60 & $16.4 \pm 1.3^{* *}$ & $141.1 \pm 8.6^{*}$ & $2.9 \pm 0.5^{*}$ \\
\hline
\end{tabular}

(A)

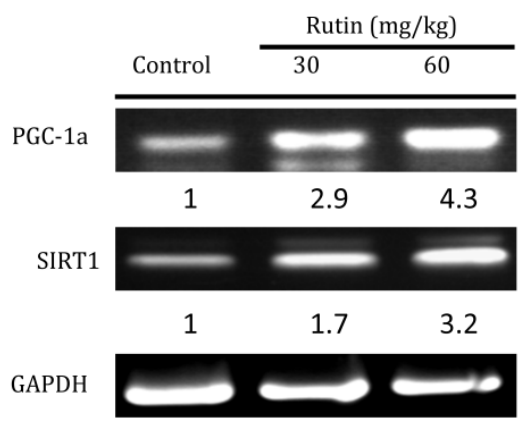

(B)

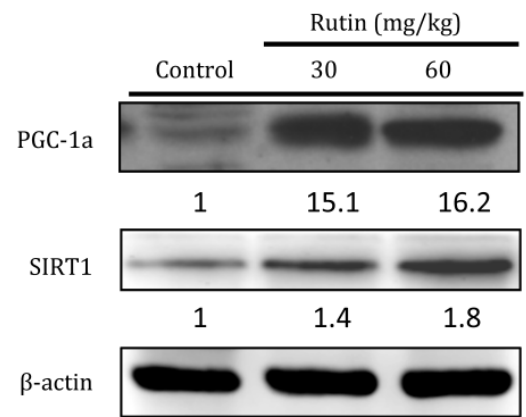

Figure I. Short-term feedings of the dietary flavonoid rutin increase expression of genes associated with mitochondrial biogenesis. Peroxisome proliferator-activated receptor- $\alpha$ coactivator (PGC-I $\alpha$ ) and sirtuin I (SIRTI) expression were measured in soleus muscle using RT-PCR following 7 days of Rutin feedings. *Significantly different from control group

\section{Effects of rutin on PGC-I and SIRT I expression}

In our experimental mice, 7 days rutin administration resulted in increased PGC-1a (Fig. 1) and SIRT1 (Fig. 1B) mRNA expression in the slow-twitch muscle $(P<0.05)$. We identified an approximate $100 \%$ increase in PGC-1a gene expression in the soleus muscle following the treatment of the mice with 30 $\mathrm{mg} / \mathrm{kg}$ and $60 \mathrm{mg} / \mathrm{kg}$ rutin doses, and a $50 \%$ and $100 \%$ increase in the muscle following their treatment with $30 \mathrm{mg} / \mathrm{kg}$ and $60 \mathrm{mg} / \mathrm{kg}$ rutin doses, respectively (Fig. 1). We observed approximately $200 \%$ increased SIRT1 expression in the muscle following the administration of $30 \mathrm{mg} / \mathrm{kg}$ and $60 \mathrm{mg} / \mathrm{kg}$ rutin doses.

\section{Two-dimensional gel electrophoresis and mass spectrometry}

After forced swimming exercise, 2D gel electrophoresis on mouse brain tissue and analysis of gel images using Prodigy SameSpots (Nonlinear) software (Fig. 2) revealed the upregulation of 2 proteins, and downregulation of 3 proteins, in a time-dependent manner. Further analysis of the proteins using LC-ESI-Q-TOF MS/MS analysis and the Mascot program identified the proteins as glycerate kinase 1 (spot no. 34), triosephosphate isomerase (spot no. 77), heat shock protein 65 (spot no. 169), myelin 
basic protein (spot no. 171), CB1 cannabinoid receptor-interacting protein 1 (spot no. 203), cofilin-1 (spot no. 211), Rho GDP dissociation inhibitor (GDI) alpha (spot no. 248), TPI (spot no. 252), and alpha-tubulin isotype M-alpha-2 (spot no. 252; Fig. 2) (Table 4).

\section{Effects of rutin on fatigue and anxiety}

We evaluated the antifatigue effects of rutin by analyzing the expression of the MAPK signaling proteins, including ERK, p38, and JNK1/2, in the mouse brain. Exercise training (Fatigue) and concurrent rutin supplementation and exercise (Fatigue+rutin) both upregulated the expression of phosphor-ERK (Fig. 3).

(A)

(B)

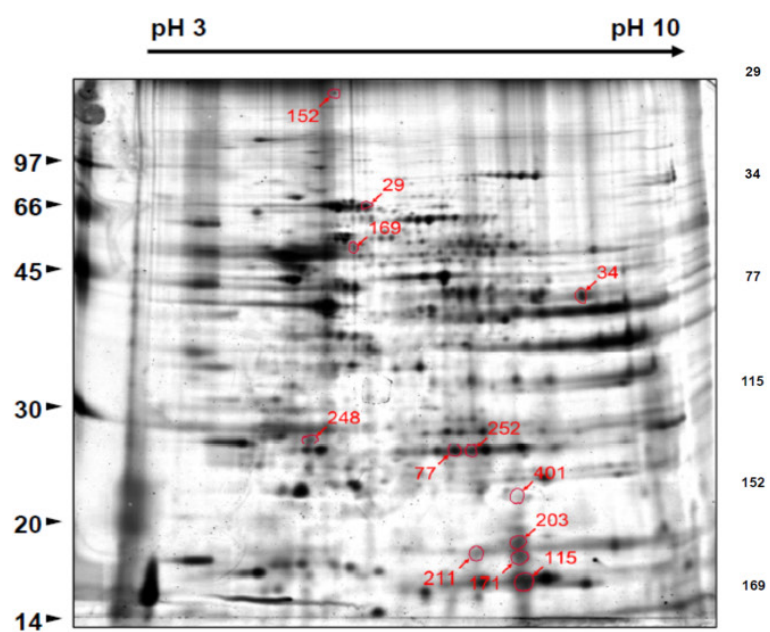

Rutin supplementation without exercise (rutin) also upregulated phosphor-ERK expression compared with the placebo mice, indicating increased MAPK signaling. We evaluated the antianxiety effects of rutin by analyzing the expression of the CB1 cannabinoid receptor (CBR). As shown in Fig. 3, the exercise and rutin-supplemented groups with or without exercise showed upregulated CBR expression compared with the placebo mice. CBR expression was significantly higher in the rutin-supplemented mice with and without exercise than in the exercised mice without rutin supplementation.

igure 2. Two-dimensional gel electrophoresis on antifatigue mice. 2-DE was performed and gels stained with SYPRO Ruby staining reagent. Gel images were analyzed by SameSpots (Nonlinear) software, and the protein spots significantly altered were selected and then subjected to LC-ESI-Q-TOF MS/MS analysis.

Table 4. Differentially expressed proteins in rutin-treated mice brain tissue compared to fatigue tissue.

\begin{tabular}{lllccc}
\hline $\begin{array}{l}\text { Spot } \\
\text { NO. }\end{array}$ & Accession NO. & \multicolumn{1}{c}{ Protein Description } & $\begin{array}{c}\text { MOWSE } \\
\text { score }\end{array}$ & $\begin{array}{c}\text { Experimental } \\
\text { Mr/pI }\end{array}$ & $\begin{array}{c}\text { Differential } \\
\text { ratio }^{\mathrm{a}}\end{array}$ \\
\hline 29 & gi|74137565 & unnamed protein product [Mus musculus] & 1631 & $67.09 / 5.78$ & 0.98 \\
& gi|163310765 & serum albumin precursor [Mus musculus] & & & \\
34 & gi|70778976 & glycerate kinase 1 [Mus musculus] & 574 & $48.02 / 8.41$ & -1.65 \\
77 & gi|54855 & triosephosphate isomerase [Mus musculus] & 640 & $25.96 / 6.76$ & 1.57 \\
115 & & & & $16.49 / 7.68$ & 2.74 \\
152 & & & $137.24 / 5.52$ & 3.64 \\
169 & gi|51455 & heat shock protein 65 [Mus musculus] & 121 & $54.00 / 5.63$ & -1.57 \\
171 & gi|199051 & myelin basic protein [Mus musculus] & 76 & $17.96 / 7.58$ & 7.71 \\
203 & gi|62000629 & CB1 cannabinoid receptor-interacting protein 1 & 52 & $18.82 / 7.58$ & 2.47 \\
& & [Mus musculus] & & & \\
211 & gi|6680924 & cofilin-1 [Mus musculus] & 310 & $18.49 / 7.04$ & -4.47 \\
248 & gi|13435747 & Rho GDP dissociation inhibitor (GDI) alpha [Mus & 261 & $27.77 / 5.07$ & 1.55 \\
& & musculus] & & & \\
252 & gi|3287374 & TPI [Mus musculus] & 633 & $25.96 / 7.00$ & 1.59 \\
401 & gi|202210 & alpha-tubulin isotype M-alpha-2 [Mus musculus] & 32 & $22.05 / 7.58$ & 75.66 \\
\hline & a up-regulated: +;down-regulated: - & & &
\end{tabular}




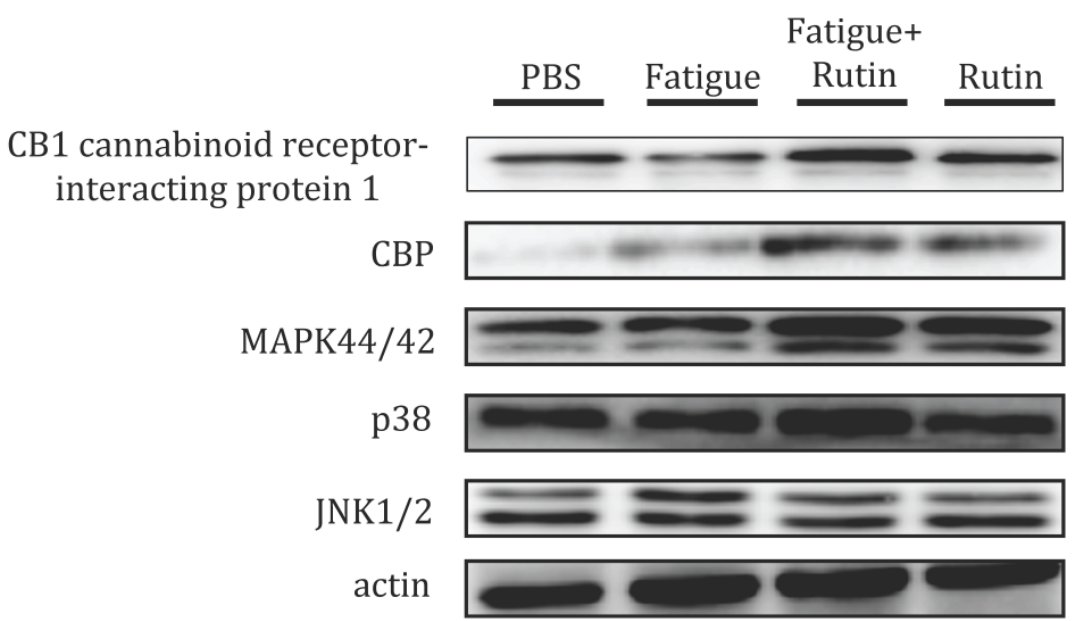

Figure 3. Rutin supplementation activation MAPK-mediated antianxiety proteins expression in mice brain. The expression level of ERK, phosphor-ERK, p38, phosphor-p38, JNKI/2, phosphor-JNKI/2 and CBR and CBI cannabinoid receptor-interacting protein I antibodies. Expression of $\beta$-actin was used as an internal control.

\section{Comment}

In this study, we identified that fatigued rats treated with rutin $(15,30$, and $60 \mathrm{mg} / \mathrm{kg})$ intraperitoneally for 7 days had longer swimming times than saline-treated fatigued animals. Plasma and brain MDA levels were higher in the fatigued animals than in the control mice; however, the oral administration of rutin for 7 days reduced the liver MDA levels in fatigued animals significantly. In our previous study, we identified that rutin, a principal component of $S$. Involucrata, attenuates the senescence effect in a D-gal aging mouse model effectively. Our results suggested that rutin exerts potent antiaging effects through antioxidative mechanisms. In addition, rutin increases the activities of the oxygen radical species-metabolizing enzymes SOD and GPx. Rutin is a hydrogen-donating antioxidant and free radical scavenger (of reactive oxygen and nitrogen species) [22-25]. It also possesses metal-chelating properties and neutralizes ferric iron to form redox-inactive iron, thereby protecting cells against oxidative damage [26, 27]. In humans, muscular exercise promotes the production of radicals and other ROS in the working muscle. Increasing evidence has suggested that ROS are responsible for exercise-induced protein oxidation and contribute extensively to muscle fatigue [28]. Muscle cells contain endogenous cellular defense mechanisms in the form of enzymatic and nonenzymatic antioxidants for the elimination of ROS. These antioxidant defense mechanisms weaken during chronic fatigue and other disease conditions. The natural cellular antioxidant enzyme SOD removes superoxide radicals by accelerating their dismutation, whereas CAT removes hydrogen peroxide. However, the radical scavenging activity of SOD is effective only if its action precedes that of CAT because SOD generates hydrogen peroxide as a metabolite, which has higher toxicity than oxygen radicals, which CAT scavenges. In this study, swimming induced ROS generation in the exercised control mice, resulting in reduced SOD and CAT activities compared with the sedentary group. However, the rutin-treated group displayed higher SOD and CAT activities compared to the controls. Thus, exogenous antioxidants from rutin might act directly to reduce fatigue or interact with endogenous antioxidants to produce synergistic antifatigue effects.

Previous studies have used swimming until exhaustion as an experimental protocol to induce stress in laboratory animals. The investigators recorded biochemical, hormonal, and behavioral changes to evaluate the physiological responses to a stressful situation $[29,30]$. Fatty acids must be primed for ATP-dependent acylation to form fatty acyl-CoA and derive energy. Swamy et al. reported that ATP synthesis increases in animals subjected to forced swimming exercises with antioxidant supplementation [31]. Antioxidant supplementation during exhaustive exercise can create aerobic conditions by reducing LA and neutralizing excess lipid peroxidation [32]. Thus, although the relationship between the ROS-related enzymes and fatigue is currently unclear, a possible mechanism that could account for the antifatigue effects of orally administrated rutin is protection against oxidative insult in the brain. PGC-1a activates mitochondrial biogenesis and increases oxidative phosphorylation by facilitating transcription, translation, and replication [33]. These effects serve to increase peak oxygen uptake and delay fatigue during prolonged exercise [34]. Rodgers et al. identified that SIRT1 and PGC-1a cofunction to promote mitochon- 
drial biogenesis [18]. Although these findings have increased interest in the development of drugs that target the SIRT1-PGC-1a coactivator complex or related signaling pathways in muscle, to mimic or potentiate the effects of exercise for the treatment of metabolic diseases [16, 18], no previous study has investigated such processes in the brain. Our data indicated that PGC-1a and SIRT1 expression are increased significantly in the skeletal muscle and brain of mice following 7 days oral rutin administration. The changes in PGC-1 $\alpha$ and SIRT1 mRNA and protein expression are likely to reflect the changes in their activities [14]. Taken together, antioxidants have been shown that can protect tissue from cytotoxicity induced by oxidative stress and some beneficial effects in cardiovascular system and other physiological activity. In this study, the result indicated that fatigue might result in anxiety and attenuated by rutin which had antioxidant effect. Therefore, whether antioxidants can reduce anxiety might be an interesting issue for further investigation.

In this study, proteomic analysis based on 2D gel electrophoresis showed significant changes in the expression of 5 proteins in mouse brain tissue following treatment with $30 \mathrm{mg} / \mathrm{kg}$ rutin. Among these, triosephosphate isomerase (spot no. 77), myelin basic protein (spot no. 171), CB1 cannabinoid receptor-interacting protein 1 (spot no. 203), Rho GDP GDI alpha (spot no. 248), TPI (spot no. 252), and alpha-tubulin isotype M-alpha-2 (spot no. 252) showed upregulated expression (Fig. 2), whereas heat shock protein 65 (spot no. 169) and cofilin-1 (spot no. 211) showed downregulated expression. Previous studies have suggested that rimonabant, a CB1 antagonist, induces anxiety and depressive symptoms. In rats, the administration of rimonabant increased immobility time in the forced swimming test and reduced the consumption of sucrose-sweetened water. These characteristics are usually indicative of depression-like phenotypes [35]. Placebo-controlled and double-blind trials on humans further showed that rimonabant induces depression, anxiety, and suicidal ideation in nonpsychiatric patients [36]. Other studies have identified that the chronic blockade of brain CB1 receptors induces depression and anxiety symptoms in normal participants. CB1 receptors are involved in motor dysfunction and schizophrenia, as well as addiction, bipolar, depression, and anxiety disorders. The cannabinoid receptor-interacting protein1a (CRIP1a) is an accessory protein of unknown function. Beyer et al. reported that cannabinoid receptor agonists specifically upregulate 5-HT(2A) receptor activity through ERK1/2 signaling, and that the activities of the cortical 5-HT(2A) receptors are associated with several neuropsychiatric disorders such as the stress response, anxiety, depression, and schizophrenia [35]. Our study findings of the activation of phospho-ERK in a rutin-supplemented mouse brain indicated the involvement of the MAPK/ERK1/2 signaling pathway in the regulation of the CB1 receptor and CRIP1a expression.

Although fatigue has received considerable research attention, its underlying molecular and neuronal mechanisms remain unclear. In this study, we evaluated fatigue objectively and quantitatively by using an animal model and several estimated biomarkers. Our results suggested that the antifatigue properties of rutin might represent a comprehensive effect of its various constituents. Overall, our study findings indicate that rutin exerts antifatigue effects by modulating the expression of PGC-1a and SIRT1, the activities of SOD and CAT (enzymes involved in the scavenging of ROS during fatigue), and other related biochemical parameters. Our results should encourage further investigation into the potential use of rutin for the treatment of physical fatigue and neurologic diseases for prevention use or therapeutic use.

\section{Acknowledgments}

This work was supported by a Grant from National Science Council of the Republic of China (101-2320-B-197-001-MY2 and 102-2320-B-002-029).

\section{Competing Interests}

The authors have declared that no competing interest exists.

\section{References}

1. Yu DSF, Lee DTF, Man NW. Fatigue among older people: A review of the research literature. International Journal of Nursing Studies. 2010; 47:216-228.

2. Fitts RH. Cellular mechanisms of muscle fatigue. Physiological reviews. 1994; 74:49-94.

3. Coombes J, Rowell B, Dodd S, Demirel H, Naito H, Shanely A, et al. Effects of vitamin E deficiency on fatigue and muscle contractile properties. Eur J Appl Physiol. 2002; 87:272-277.

4. You L, Zhao M, Regenstein J, Ren J. In vitro antioxidant activity and in vivo anti-fatigue effect of loach (Misgurnus anguillicaudatus) peptides prepared by papain digestion. Food Chem. 2011; 124:188-194.

5. Zheng X, Long W, Liu G, Zhang X, Yang X. Effect of seabuckthorn (Hippophae rhamnoides ssp. sinensis) leaf extract on the swimming endurance and exhaustive exercise-induced oxidative stress of rats. Journal of the science of food and agriculture. 2012; 92:736-42.

6. Way TD, Lee JC, Kuo DH, Fan LL, Huang CH, Lin HY, et al. Inhibition of epidermal growth factor receptor signaling by Saussurea involucrata, a rare traditional Chinese medicinal herb, in human hormone-resistant prostate cancer PC-3 cells. Journal of agricultural and food chemistry. 2010; 58:3356-65.

7. Katsube T, Imawaka N, Kawano Y, Yamazaki Y, Shiwaku K, Yamane Y. Antioxidant flavonol glycosides in mulberry (Morus alba L.) leaves isolated based on LDL antioxidant activity. Food Chem. 2006; 97:25-31.

8. Nassiri-Asl M, Shariati-Rad S, Zamansoltani F. Anticonvulsive effects of intracerebroventricular administration of rutin in rats. Progress in neuro-psychopharmacology \& biological psychiatry. 2008; 32:989-93.

9. Gupta R, Singh M, Sharma A. Neuroprotective effect of antioxidants on ischaemia and reperfusion-induced cerebral injury. Pharmacological research : the official journal of the Italian Pharmacological Society. 2003; 48:209-15.

10. Koda T, Kuroda $Y$, Imai $H$. Protective effect of rutin against spatial memory impairment induced by trimethyltin in rats. Nutr Res. 2008; 28:629-34.

11. Yang YC, Lin HY, Su KY, Chen CH, Yu YL, Lin CC, et al. Rutin, a Flavonoid That Is a Main Component of Saussurea involucrata, Attenuates the Senescence Effect in D-Galactose Aging Mouse Model. Evidence-based complementary and alternative medicine : eCAM. 2012; 2012:980276. 
12. Nybo L, Rasmussen P. Inadequate cerebral oxygen delivery and central fatigue during strenuous exercise. Exercise and sport sciences reviews. 2007; 35:110-8.

13. Tanaka M, Watanabe $\mathrm{Y}$. Reduced energy utilization in the brain is a feature of an animal model of fatigue. The International journal of neuroscience. 2008; 118:683-92.

14. Lagouge M, Argmann C, Gerhart-Hines Z, Meziane H, Lerin C, Daussin F, et al. Resveratrol improves mitochondrial function and protects against metabolic disease by activating SIRT1 and PGC-1alpha. Cell. 2006; 127:1109-22.

15. Lopez-Lluch G, Hunt N, Jones B, Zhu M, Jamieson H, Hilmer S, et al. Calorie restriction induces mitochondrial biogenesis and bioenergetic efficiency. Proceedings of the National Academy of Sciences of the United States of America. 2006; 103:1768-73.

16. Narkar VA, Downes M, Yu RT, Embler E, Wang YX, Banayo E, et al. AMPK and PPARdelta agonists are exercise mimetics. Cell. 2008; 134:405-15.

17. Rasbach KA, Schnellmann RG. Isoflavones promote mitochondrial biogenesis. The Journal of pharmacology and experimental therapeutics. 2008; 325:536-43.

18. Rodgers JT, Lerin C, Haas W, Gygi SP, Spiegelman BM, Puigserver P. Nutrient control of glucose homeostasis through a complex of PGC-1alpha and SIRT1. Nature. 2005; 434:113-8.

19. Rohas LM, St-Pierre J, Uldry M, Jager S, Handschin C, Spiegelman BM. A fundamental system of cellular energy homeostasis regulated by PGC-1alpha. Proceedings of the National Academy of Sciences of the United States of America. 2007; 104:7933-8.

20. Dorta DJ, Pigoso AA, Mingatto FE, Rodrigues T, Prado IM, Helena AF, et al. The interaction of flavonoids with mitochondria: effects on energetic processes. Chemico-biological interactions. 2005; 152:67-78.

21. Trumbeckaite S, Bernatoniene J, Majiene D, Jakstas V, Savickas A, Toleikis A. The effect of flavonoids on rat heart mitochondrial function. Biomedicine \& pharmacotherapy $=$ Biomedecine \& pharmacotherapie. 2006; 60:245-8.

22. Lopez-Velez M, Martinez-Martinez F, Del Valle-Ribes C. The study of phenolic compounds as natural antioxidants in wine. Critical reviews in food science and nutrition. 2003; 43:233-44.

23. McPhail DB, Hartley RC, Gardner PT, Duthie GG. Kinetic and stoichiometric assessment of the antioxidant activity of flavonoids by electron spin resonance spectroscopy. Journal of agricultural and food chemistry. 2003; 51:1684-90.

24. Mira L, Silva M, Rocha R, Manso CF. Measurement of relative antioxidant activity of compounds: a methodological note. Redox report : communications in free radical research. 1999; 4:69-74.

25. Brown JE, Khodr H, Hider RC, Rice-Evans CA. Structural dependence of flavonoid interactions with $\mathrm{Cu} 2+$ ions: implications for their antioxidant properties. The Biochemical journal. 1998; 330 ( Pt 3):1173-8.

26. Gong G, Qin Y, Huang W, Zhou S, Yang X, Li D. Rutin inhibits hydrogen peroxide-induced apoptosis through regulating reactive oxygen species mediated mitochondrial dysfunction pathway in human umbilical vein endothelial cells. European journal of pharmacology. 2010; 628:27-35.

27. Jeong YJ, Choi YJ, Kwon HM, Kang SW, Park HS, Lee M, et al. Differential inhibition of oxidized LDL-induced apoptosis in human endothelial cells treated with different flavonoids. The British journal of nutrition. 2005; 93:581-91.

28. Powers SK, DeRuisseau KC, Quindry J, Hamilton KL. Dietary antioxidants and exercise. Journal of sports sciences. 2004; 22:81-94.

29. Marcondes FK, Vanderlei LC, Lanza LL, Spadari-Bratfisch RC. Stress-induced subsensitivity to catecholamines depends on the estrous cycle. Canadian journal of physiology and pharmacology. 1996; 74:663-9.

30. Tanno AP, Bianchi FJ, Costa Sampaio Moura MJ, Marcondes FK. Atrial supersensitivity to noradrenaline in stressed female rats. Life sciences. 2002; 71:2973-981.

31. Swamy M, Yusof WR, Sirajudeen KN, Mustapha Z, Govindasamy C. Decreased glutamine synthetase, increased citrulline-nitric oxide cycle activities, and oxidative stress in different regions of brain in epilepsy rat model. Journal of physiology and biochemistry. 2011; 67:105-13.

32. Radak Z, Asano K, Inoue M, Kizaki T, Oh-Ishi S, Suzuki K, et al. Superoxide dismutase derivative prevents oxidative damage in liver and kidney of rats induced by exhausting exercise. European journal of applied physiology and occupational physiology. 1996; 72:189-94.

33. Puigserver $\mathrm{P}$, Spiegelman BM. Peroxisome proliferator-activated receptor-gamma coactivator 1 alpha (PGC-1 alpha): transcriptional coactivator and metabolic regulator. Endocrine reviews. 2003; 24:78-90.

34. Calvo JA, Daniels TG, Wang X, Paul A, Lin J, Spiegelman BM, et al. Muscle-specific expression of PPARgamma coactivator-1alpha improves exercise performance and increases peak oxygen uptake. J Appl Physiol. 2008; 104:1304-12.

35. Beyer CE, Dwyer JM, Piesla MJ, Platt BJ, Shen R, Rahman Z, et al. Depression-like phenotype following chronic CB1 receptor antagonism. Neurobiology of Disease. 2010; 39:148-155.

36. Christensen R, Kristensen PK, Bartels EM, Bliddal H, Astrup AV. [A meta-analysis of the efficacy and safety of the anti-obesity agent Rimonabant]. Ugeskrift for laeger. 2007; 169:4360-3. 